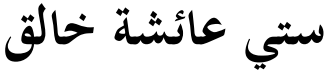

\section{الفعل الصيحيح في سورة المائدة (دراسة تحليلية صرفية)}

\author{
Sitti Aisyah Chalik ${ }^{1}$
}

Universitas Islam Negerai Alauddin Makassar

Email: sittiaisyahchalik@gmail.com ${ }^{1}$

DOI: https://doi.org/10.24252/saa.v6i2.7127

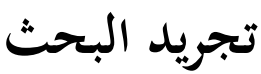

هذه الرسالة تبحث عن الفعل الصيحيح في سورة المائدة (دراسة تحليلية

صرفية). في هذه الرسالة تبين عن الفعل خصوصا عن الفعل الصيحيح. و المشكلات التي تستعمل الباحثة لبحث هذه الرسالة فهي: 1)كيف أنواع الفعل الصحيح في سورة المائدة ؟، 2) ما وزن الفعل الصحيح في سورة المائدة ؟

شكل هذه البحث هو البحث المكتبي يعني جمع عدة من الكتب

المتعلقة بهذا الموضوع. و أما مناهج البحث الذي تستعمل الباحثة لبحث هذه الرسالة فهي طريقة جمع المواد هي جمع الباحثة كل الفعل الصحيح في سورة المائدة و طريقة التنظيم المواد و تحليلها هي نظم البحث ثم تحليل الفعل الصحيح في سورة المائدة و نوعه. وشرح انواعها باستخدام التحليل بالنظر إلى كتب الصرفية المتعلقة 
في هذا البحث العلمي وكتب التفاسير. والطريقة التي سلكتها الباحثة لجمع هذه البيانات هي بتحديد القواعد الصرفية العامة التي تتضمن الشرحات عن الفعل الصحيح ثم تحلل انواعها.

من هذا البحث عرفنا أن الفعل الصحيح، و هو ما كان أحرفه الأصلية

كلها صحيحة وأصله ليس فيه حرف العلة و هو ثلاثة أقسام فهي السالم و المضاعف و المهموز. وجدات الباحثة 384 (ثلاث مائة وأربعة وثمانون) الفعل الصحيح في سورة المائدة منها: 279( مائتان وتسعة وسبعون ) السالم ، 46( ستة وأربعون) المضاعف، 59(تسعة وخمسون) المهموز . أوزان في سورة المائدة هي:

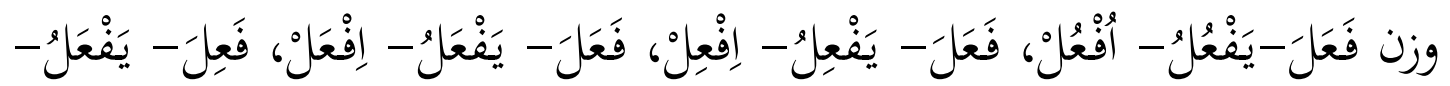

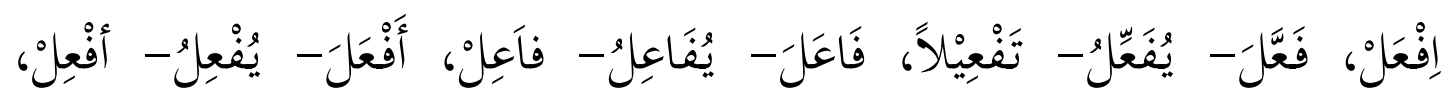

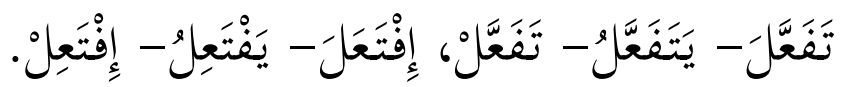
الكلمة الرئيسية : الفعل الصحيح، سورة المائدة، دراسة تحليلية صرفية

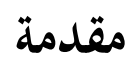
علم الصرف هو علم يبحث عن الكلم من حيث ما يعرض له من تصريف وإعلال وإدغام وإبدال وبه نعرف ما يجب أن تكون عليه بنية الكلمة قبل تنظيمها 
في الجملة. 1 وقال انه نايف معروف علم الصرف هو علم يبحث في الكلمة قبل دخولها في تركيب الكلام، ثم قال نفس المرجع تحويل الأصل الواحد من الكلمة إلى صيغ مختلفة لأداء ضروب من المعاني المقصودة والثثنية والمحع وأخذذ المشتقات وبناء الفعل البمهول وغيرها.

\section{البحث}

\section{الفصل الأول: تعريف علم الصرف}

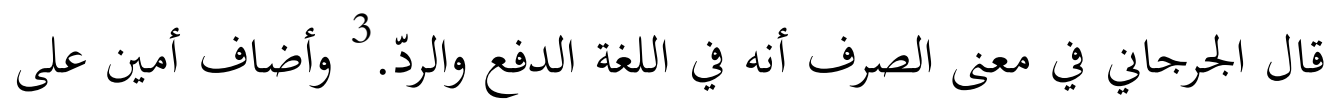
السيد أن المعاني التي استعمل فيها الصرف بحردا أو مزيدا هي كما يأتي:

صرف الحديث: أن يزاد فيه ويحسّن

صرف عن الشيئ صرفا: رده عنه

صرفه الدهر نوائبه: الليل النهار صرفان

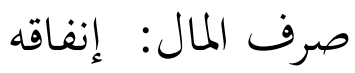

صرف الأجير والصبي: تخلية سبيله

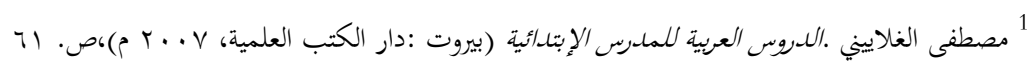

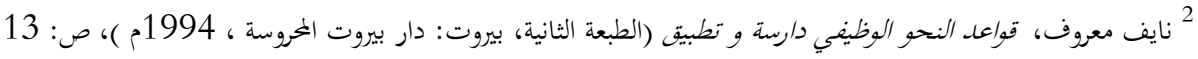

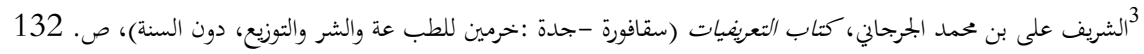




$$
\begin{aligned}
& \text { الصريف: الصوت ومنه صريف الأقلام } \\
& \text { أصرف شع ره: أقوى فيه، والإقواء عيب من عيوب القافية } \\
& \text { تصريف الرياح : تحويلها من وجه إلى وجه } \\
& \text { تصريف الآيات : تبيينها } \\
& \text { صرّفته في الأمر تصريفا فتصرف : قلبته و تقلب } \\
& \text { واصطرفَ : تصرّف في طلب الكسب } \\
& \text { واستصرقتُ الله المكارة : سألته أن يصر فها عنّ.. }
\end{aligned}
$$

ومن الناحية الإصطلاحية حية، اما أن يرادبه المعنى العلمي أو المعنى

العملي، فالأول يقصد به: العلم بالأصول وبالقواعد الكلية التى يعرف بها التغيير الذى يتعلق بصيغة الكلمة وأحوال مبنيتها وصغتهالتي ليست بإعراب ولابناء. 4

موضوع علم الصرف، الأفعال المتصرفة، والأسماء المتمكنة، فلا يدخل الحروف، لأهما بجهول لة الأصل، ولا يدخل الأسماء المتوغلة في البناء، كالضمائر وأسماء الأفعال الجامدة.

الفصل الثاني: مفهم الفعل الصحيح

$$
\begin{aligned}
& \text { 4 مكمل الدين، علم الصرف (الطبعة الأول; جامعة علاءالدين برس، مكاسر.2013)، ص.2013 (2013)، ص. } \\
& \text { 5مكمل الدين، علم الصرف (الطبعة الأول؛جامعة علاءالدين برس : مكاسر .2013)، صاعل ص. }
\end{aligned}
$$


في اللغة العربية كانت الثامنة وعشرون حرفا، من الألف إلى الياء. وتلك

الثامنة وعشرون، بخط عارض تحصل على تقسيمها جنس حرفان وذلك جنسان هو الحرف العلة والصحيح. 6 الفعل باعتبار قوة حروفه و ضعفها ( باعتبار تكوين حروفه الأصلية) إلى قسمين: صحيحح و معتل. أحرف العلة هي الواو والألف والياء وقد جمعت في قولمم "أوي". وإن سكن حرف العلة وفتح ما قبله سمى حرف علة ولين. كما في نحو: ثوب، سيف، جورب. فالفتحة غير بحانسة لكل من الواو والياء ومثل ذلك فردوس، هيمن. الفعل الصحيح هو ما كانت أحرفه الأصلية أحرفاً صحيحة. 8 و هو كلمة الفعل الذي الفاء، عين واللام الفعل غير التركيب من أحرف العلة والهمزة والتضعيف. فإن خلا الفعل الصحيح من الهمزة والتضعيف سمى سالم. الفصل الثالث: أنواع الفعل الصحيح ينقسم الفعل الصحيح ألى ثلاثة أقسام: سالم و مهموز و مضاعف. 10 1

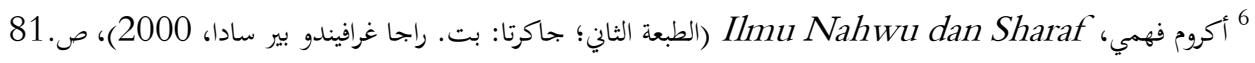

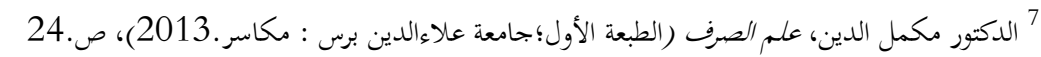

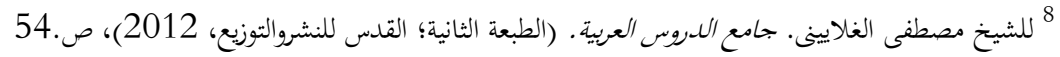

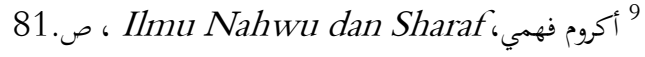

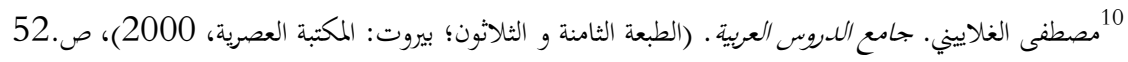


السالم هو مالم يكن أحد أحرفه الأصلية حرف علّة ولا هزة، ولا

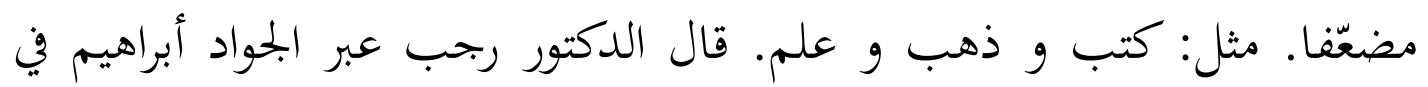

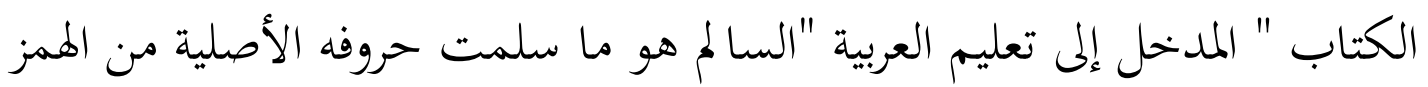
والتضعيف .مثلها :ذهب - أذهب، سلم -سالم بتحد أن أحرف الفعل الأصلية كلها أحرف صحيحة، وليس واحد منها همزة ولا مضعفا .ومتى كان الفعل الفئ

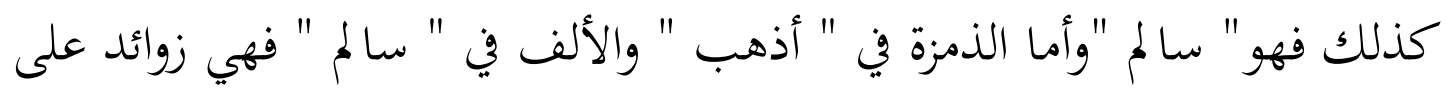
الأصل. 2 المهموز هو ما كان أحد أحرفه الأصلية هزة و هو ثلاثة أقسام: مهموز الفاء، ومهموز العن، ومهموز اللام. 11 أ. مهموز الفاء مهموز الفاء هو ماكانت فاء فعله همزة (مثل: أخذ- أكل-أمل) ب. مهموز العين تمهمز العن هو ماكانت عين فعله هزة (مثل:سأل-بئس-سئم) مهمز اعين مهموز اللام هو ماكانت لام فعله همزة (مثل:قرأ-هنأ-بدأ)

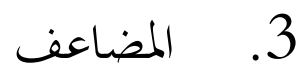

المضاعف هو ما كان أحد أحرفه الأصلية مكررا لغير زيادة. 12 و هو قسمان :

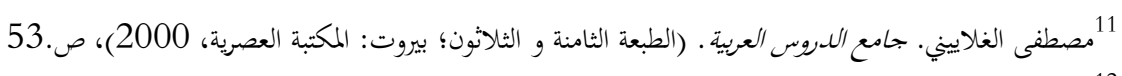

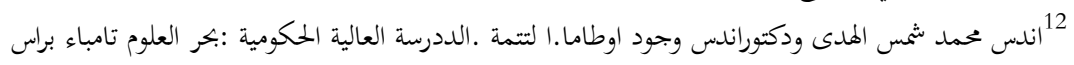


أ. مضاعف ثلاثي

مضاعف الثلاثي هو ما كان وسطو وآخره من جنس واحد (مثل : رَدَّة،

$$
\text { دَلَّ). } 13
$$

ب. مضاعف رباعي

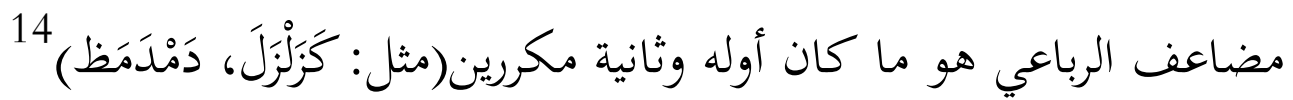

\section{المناهج المستعملة في كتابة الرسالة}

مدخل البحث ونوعه في هذا البحث من مدناله البهل الكيفي. بحث الكيفي هو

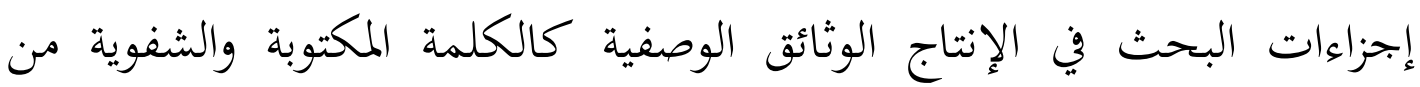

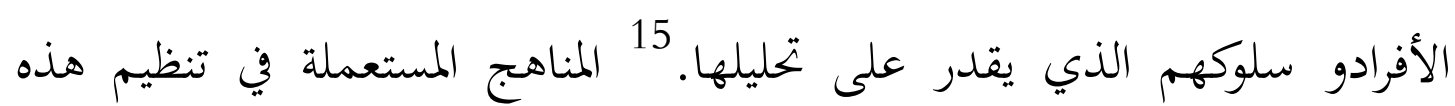

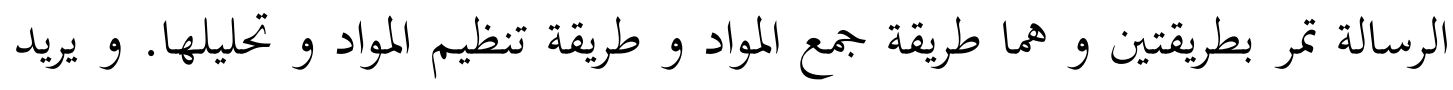
الكاتب أن يشرحهما واحد فواحد كما يأتي:

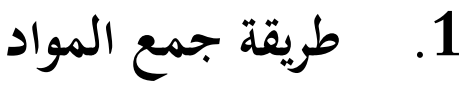

\section{2. طريقة تنظيم المواد و تحليلها}

في هذه الطريقة تستخدمها الكاتبة الطرق الآتية :

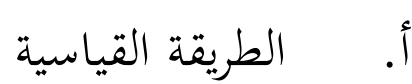

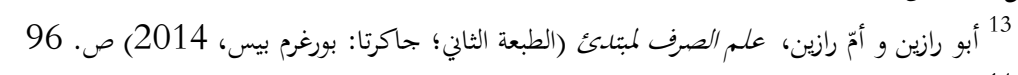

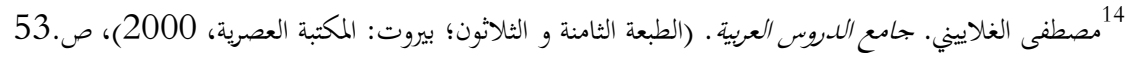

15 ليكسي موليونج، Metodologi Penelitian Kualitatif 
والمراد بها تنظيم المواد أو المعطيات بواسطة إصدار الحناصة بالانطلاق من الأمور العامّة الى الأمور الخصة أو بعبارة أخرى إصدار

$$
\text { بل الخلاصة من الأمور الكليات إلى الأمور الجزئية. }
$$

والمراد بها تنظيم المواد أو المعطيات بواسطة إصدار الخلاصة من

الأمور الخصة الى الأمور العامّة، أو بعبارة أخرى إصدار الخلاصات البحثية

من الأمور الجزئية إلى الأمور الكلية. وقصارى القول اها ضدّ الطريقة السابقة الذكر، أي الطريقة القياسية.

$$
\begin{aligned}
& \text { أغراض البحث وفوائده }
\end{aligned}
$$

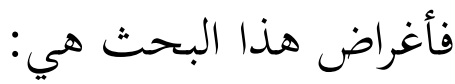

$$
\begin{aligned}
& \text { 1 } \\
& \text { 2. لمعرفة وزن الفعل الصحيح في سورة المائدة. } \\
& \text { فوائد البحث يعني: } \\
& \text { 1. لكي يزيد الطلاب علومهم في الصرف لأن به يستطاع الطلاب إجادة } \\
& \text { العلوم العربية. }
\end{aligned}
$$


2. لكي يسهل علينا أن نفهم و ندريس عن الفعل الصحيح في سورة المائدة

بواسطة هذا الرسالة.

\section{نتائج البحث}

الفصل الأول: الآيات التي تحتوي على الفعل الصحيح في سورة المائدة

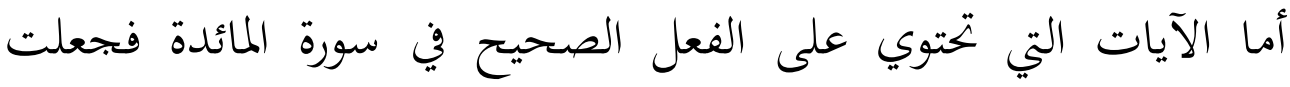
الباحثة تحت الكلمة الخط دلالة على أها صحيح:

\begin{tabular}{|c|c|c|c|c|c|}
\hline \multicolumn{3}{|c|}{ الصحيحة } & \multirow[t]{2}{*}{ الآيات } & \multirow{2}{*}{ رقآلية } & \multirow[t]{2}{*}{ الرقم } \\
\hline المهموز & المضاعف & السالم & & & \\
\hline عَاءمَنْوَ| & أُجِلَّت & "َحَكُكُمُ & 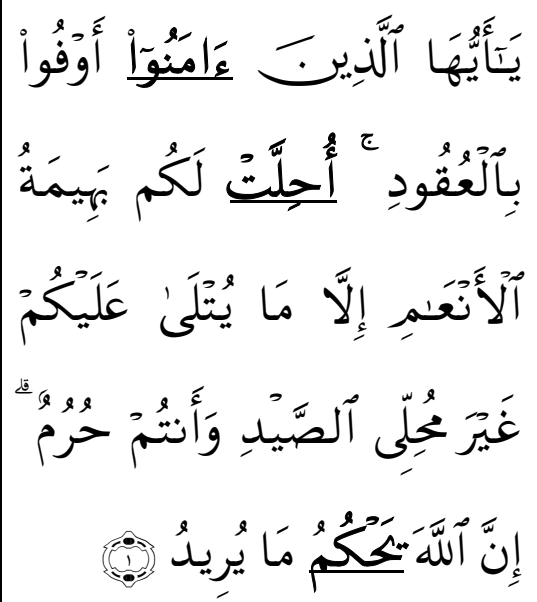 & 1 & .1 \\
\hline عَامَنْوا & حَحَلَتِّمُ & تَجِرِمِنَسَّمُم & 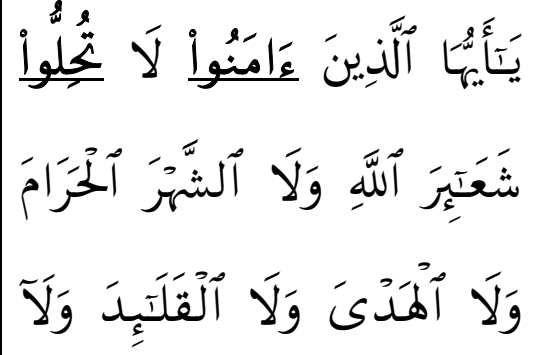 & 2 & .2 \\
\hline
\end{tabular}




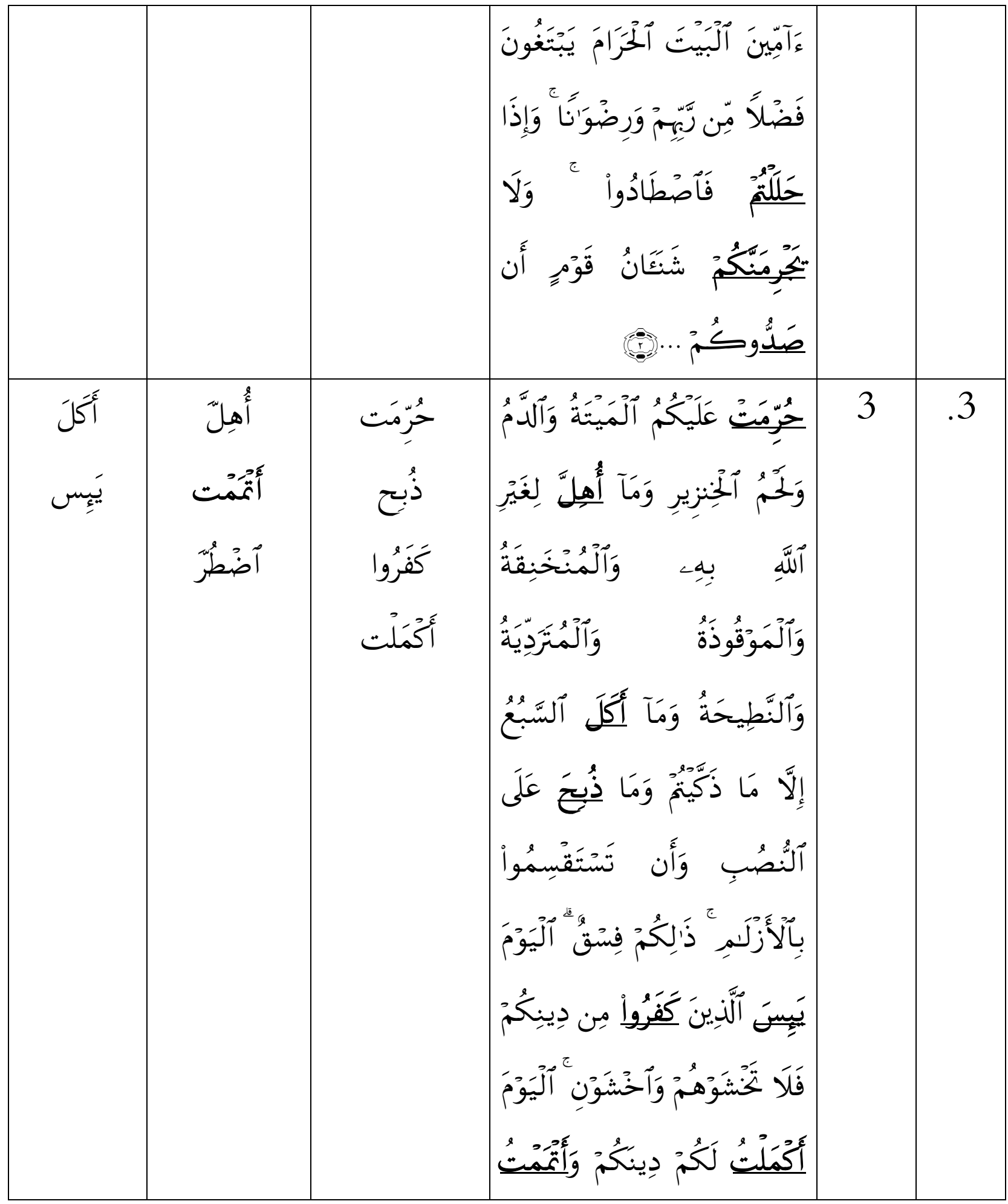




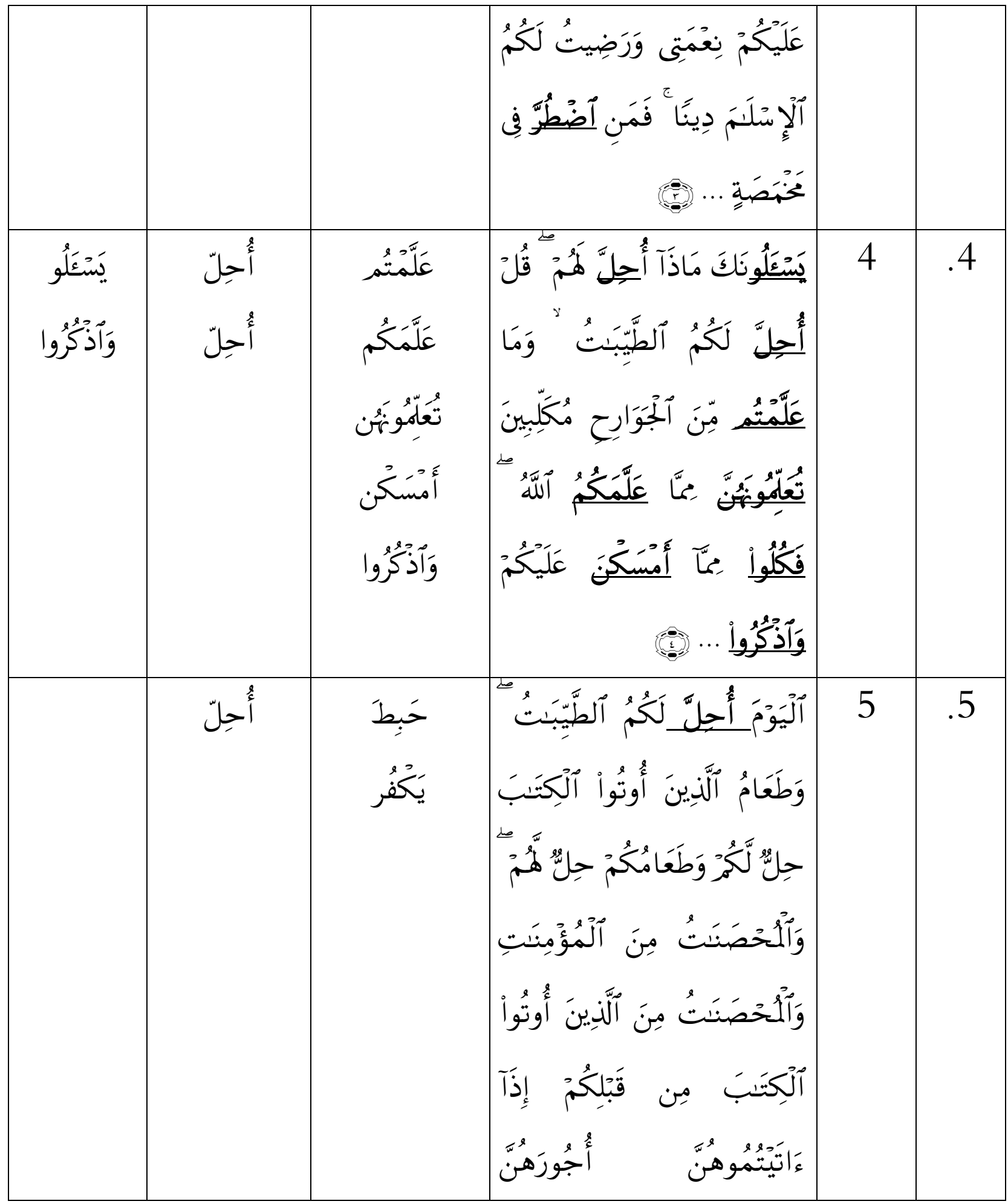




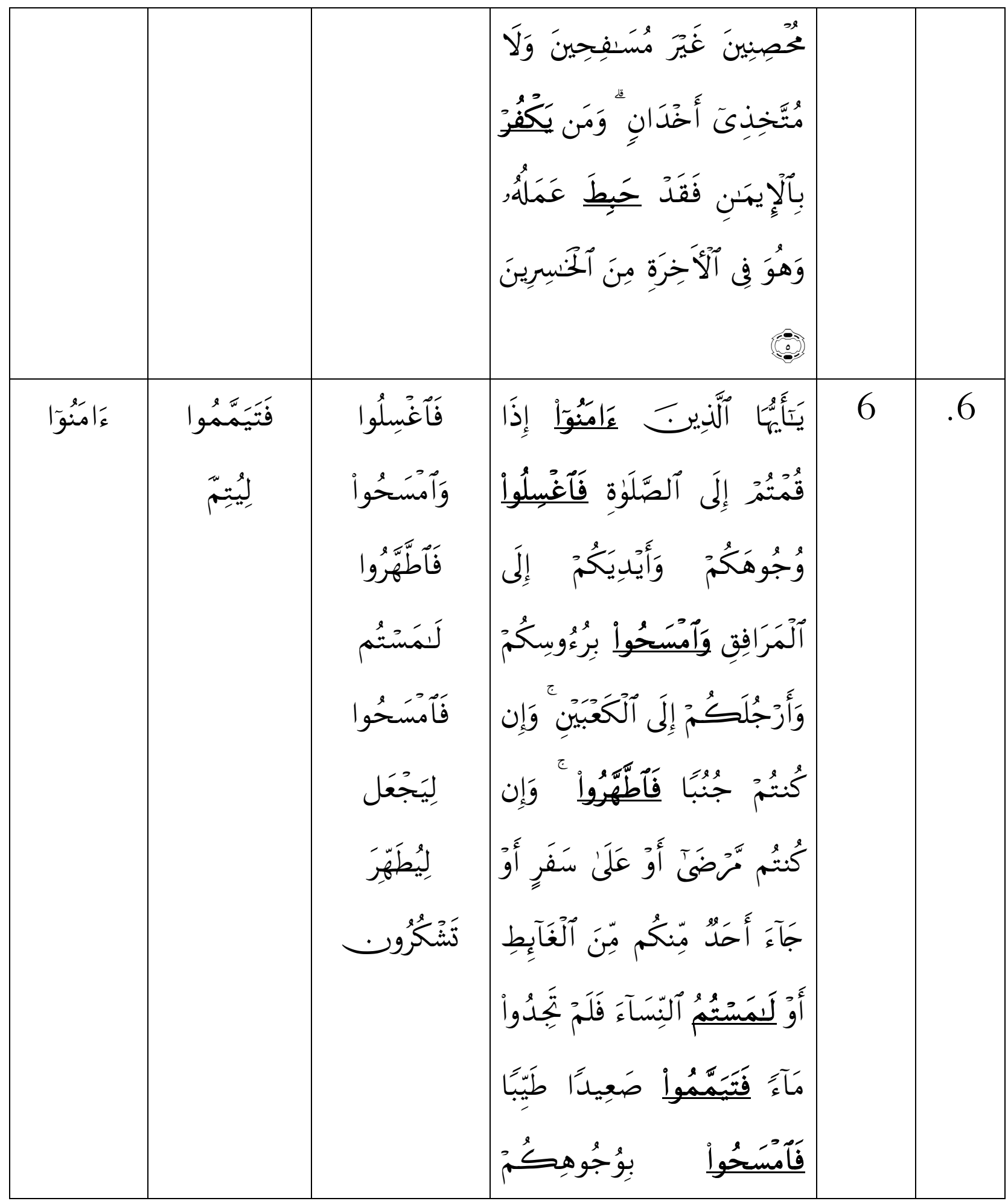




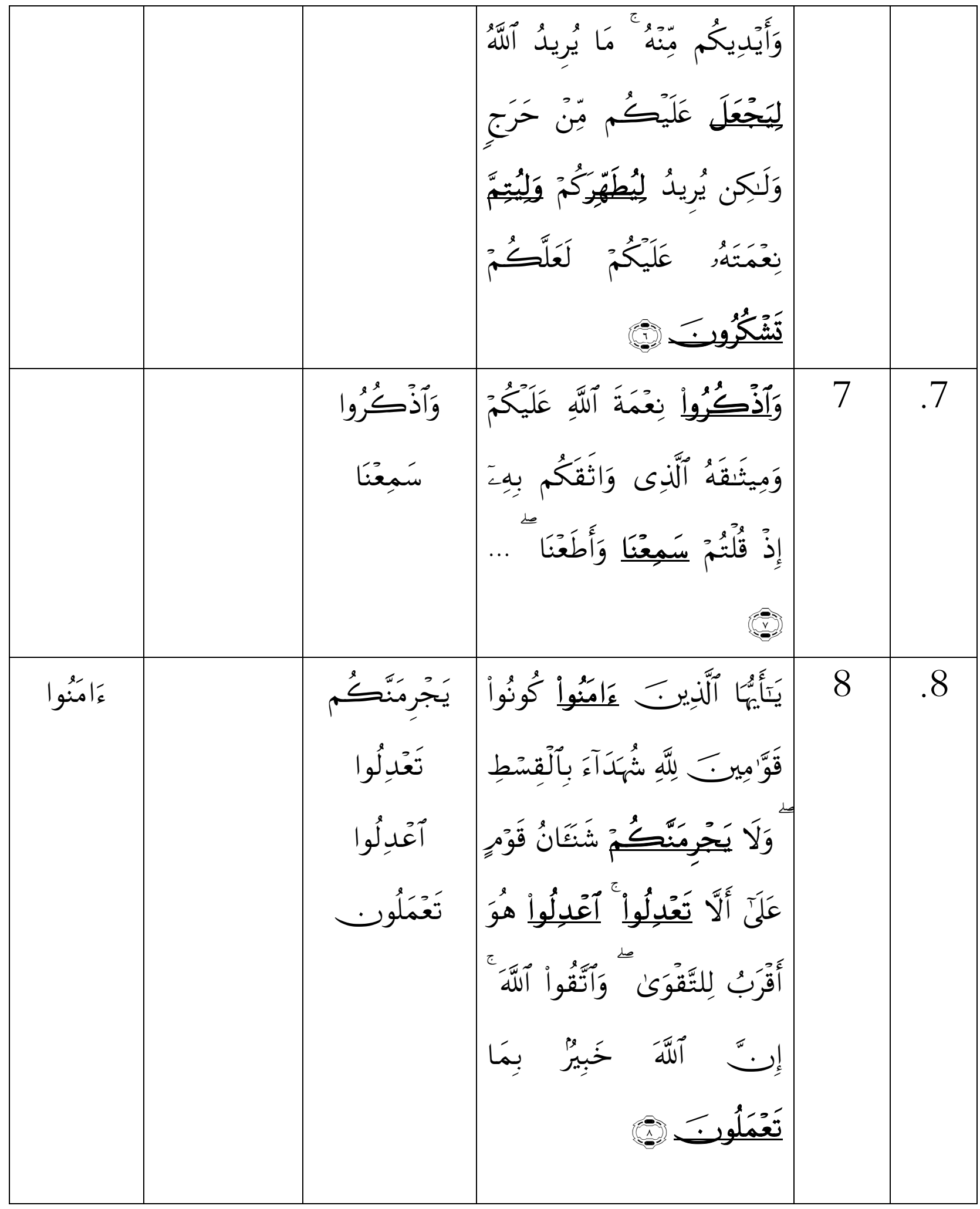




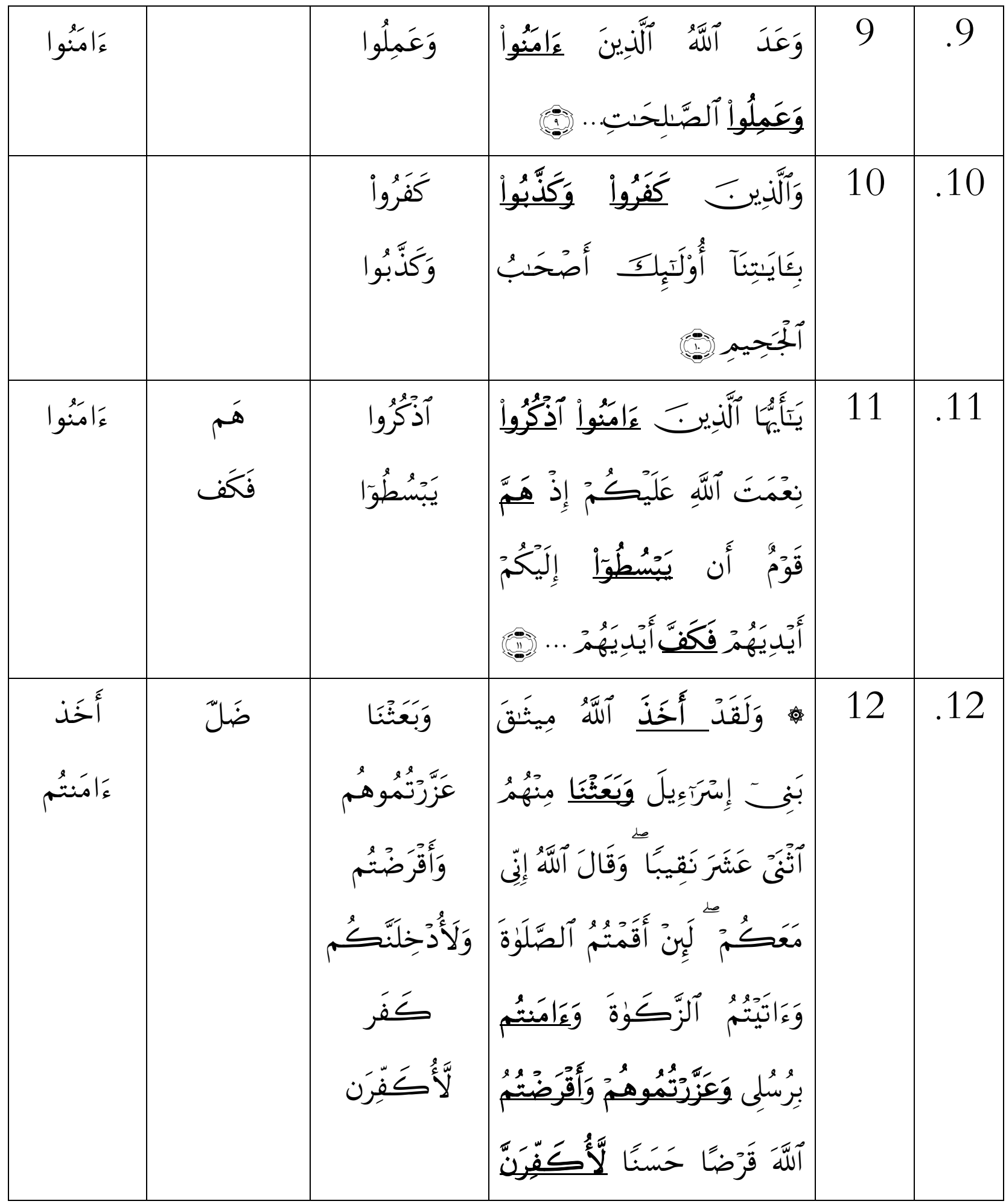




\begin{tabular}{|c|c|c|c|c|c|}
\hline & & & 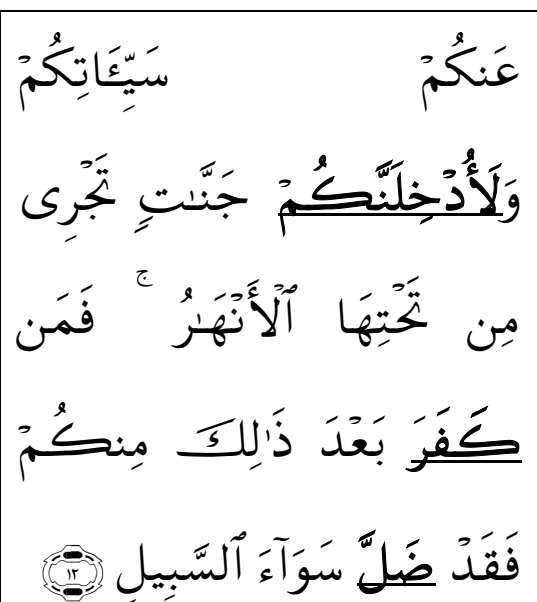 & & \\
\hline & تُحِبِ & 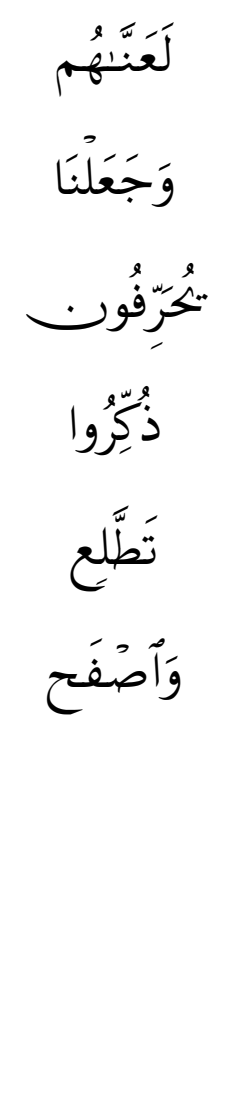 & 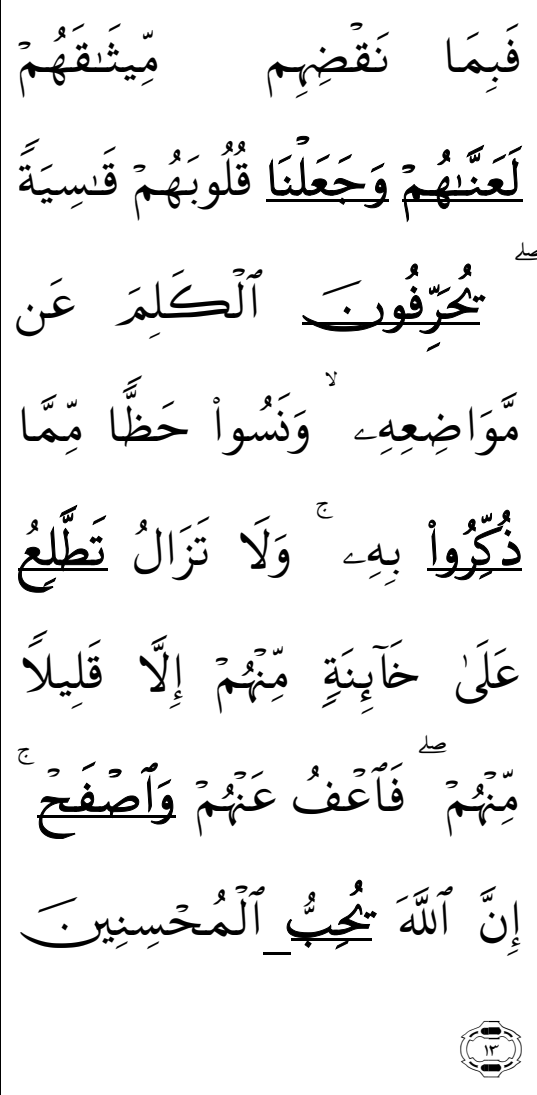 & 13 & .13 \\
\hline أَخَخْنَنَا & & 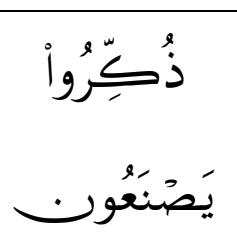 & 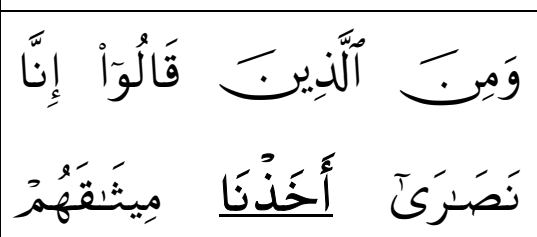 & 14 & .14 \\
\hline
\end{tabular}




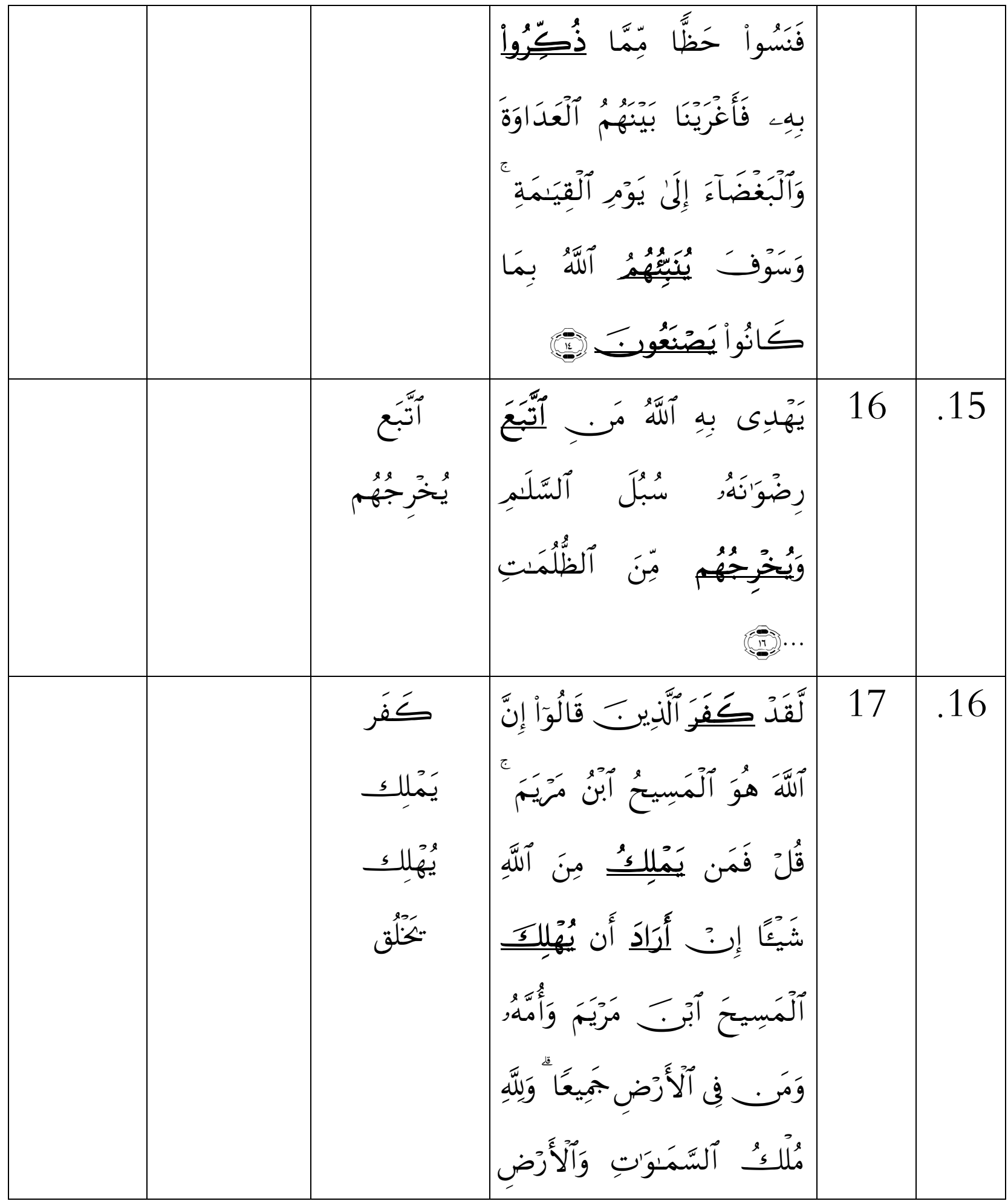




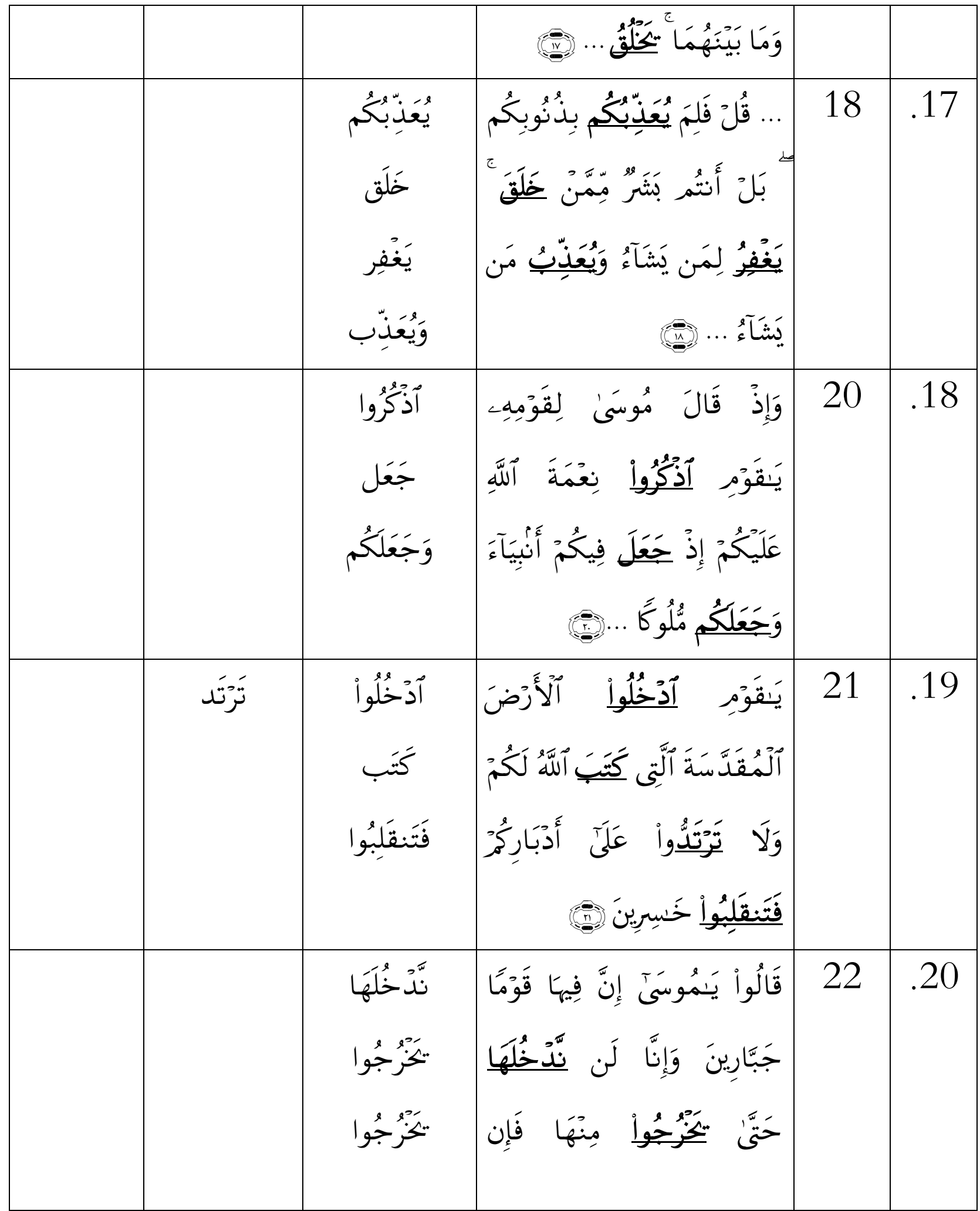




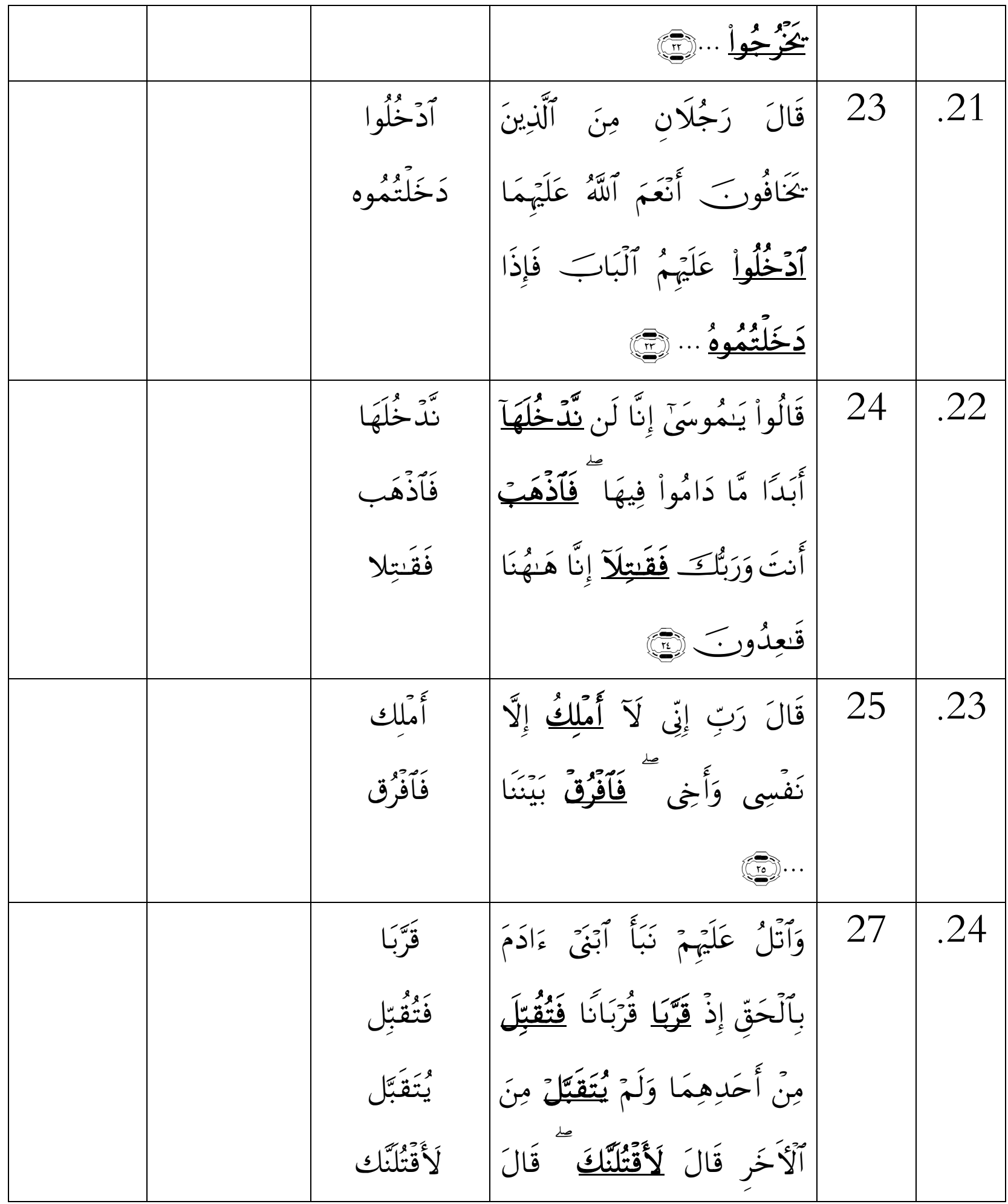




\begin{tabular}{|c|c|c|c|c|c|}
\hline & & يَتَقَبَّلَ & 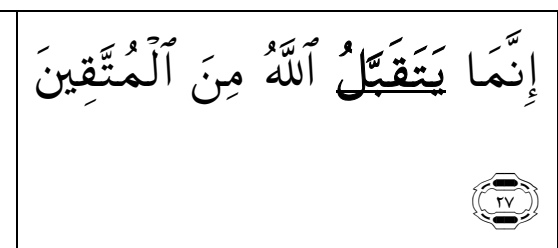 & & \\
\hline & & 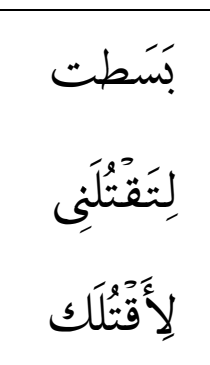 & 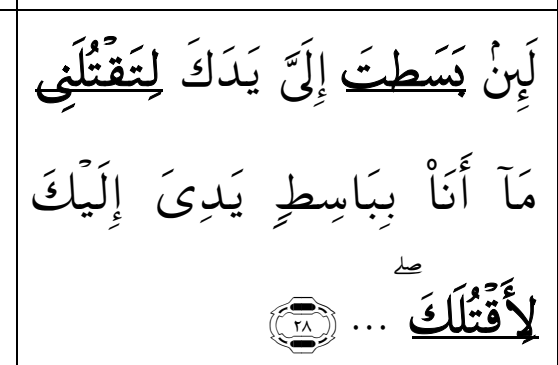 & 28 & .25 \\
\hline & & فَفَتَلَهَ & 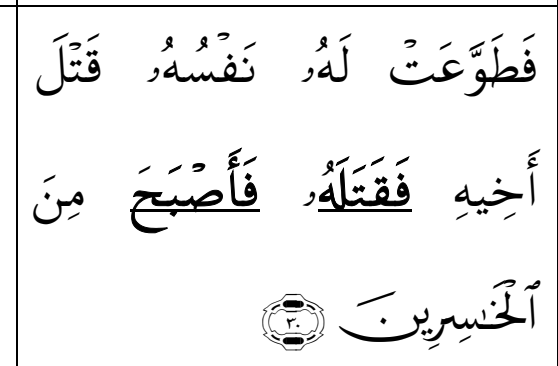 & 30 & .26 \\
\hline & & فَفَبَبَحَتَثَ & 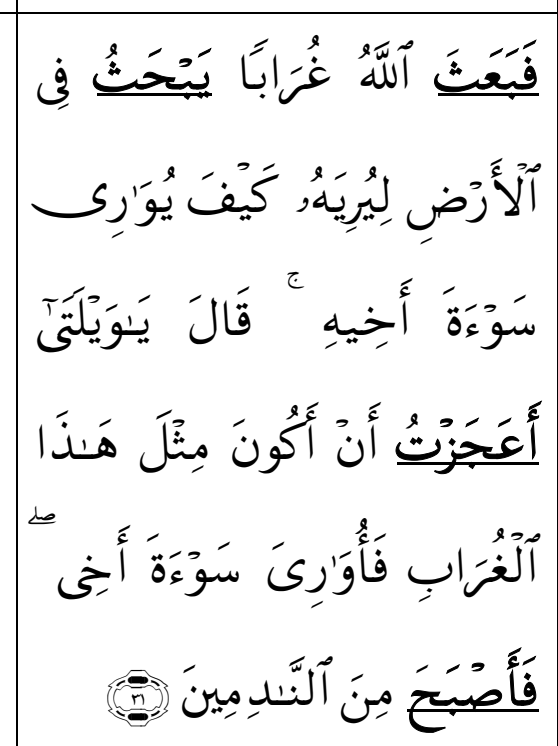 & 31 & .27 \\
\hline & & قَتَتَبَنَا & 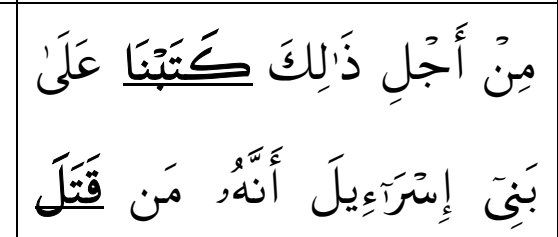 & 32 & .28 \\
\hline
\end{tabular}




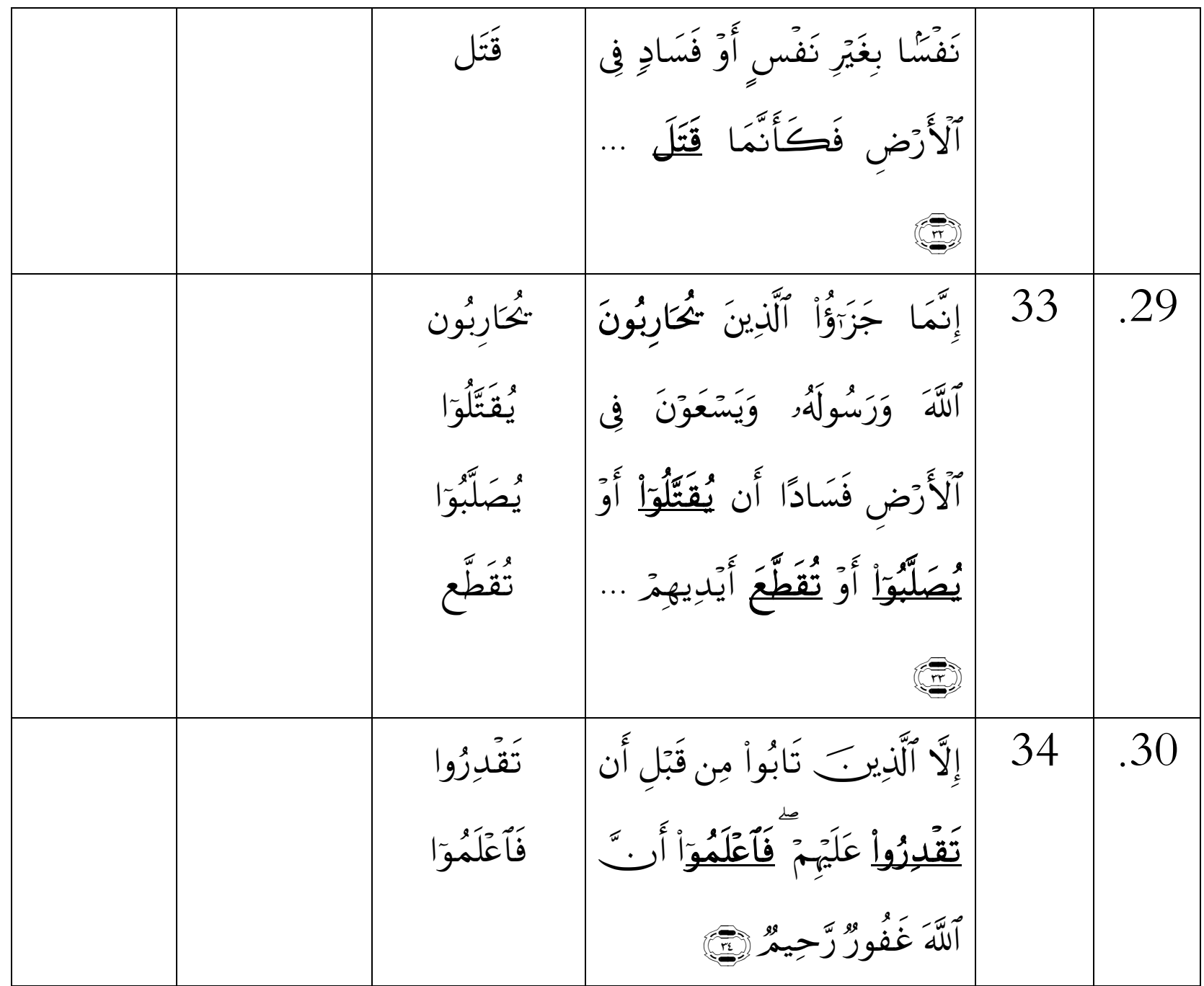

عل الصحيح في سورة المائدة منها: 279 (مائتان وتسعة وسبعون ) السالم ، 46 ستة وأربعون) المضاعف، 59(تسعة وخمسون) المهموز.

\section{الخلاضة}

أ. الفعل الصحيح هو ما كانت أحرفه الأصلية أحرفاً صحيحة و هو كلمة

الفعل الذي الفاء، عين واللام الفعل غير التركيب من أحرف العلة والممزة والتضعيف. 
ب. ينقسم الفعل الصحيح ألى ثلاثة أقسام: السالم و المضاعف و المهموز. ت. الآيات وجدت الباحثة 384 (ثلاث مائة وأربعة وثمانون) الفعل الصحيح في سورة المائدة منها: 279 مائتان وتسعة وسبعون ) السالم ، 46( ستة

$$
\begin{aligned}
& \text { وأربعون) المضاعف، 59(تسعة وخمسون) المهموز. } \\
& \text { ث. أوزان في سورة المائدة هي: } \\
& \text { 1. وزن فَعَلَ- يَفْعُلُ- أُفْعُنْ } \\
& \text { 2. وزن فَعَلَ- يَفْعِلُ- إِفْعِنْ } \\
& \text { 3. وزن فَعَلَ- يَفْعَلْ- إِفْعَلْ } \\
& \text { 4. وزن فَعِلَ- يَفْعَلُ- إفْعَلْ }
\end{aligned}
$$

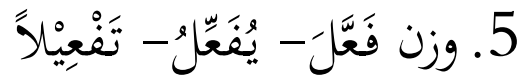

$$
\begin{aligned}
& \text { 6. وزن فَاعَلَ- يُفَاعِلُ- فَاَعِلْ } \\
& \text { 7. وزن أَفْفَلَ- يُفْعِلْ- أ } 82
\end{aligned}
$$

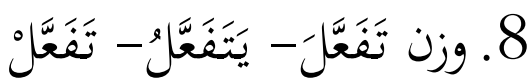

$$
\begin{aligned}
& \text { 9. وزن إفْتَعَلَ- يَفْتَعِلُ- إِفْتَعِلْ }
\end{aligned}
$$

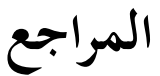

القرآن الكريم. سورة يوسف (12):2.جاكرتا: ف ت. فنجا جمرلغ، 2014. 
البغدادي، محمود شكري الألوسي. روح المعاني، الجزء السادس؛ بيروت-لبنان:

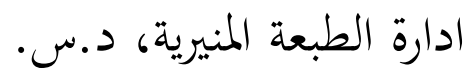

الجرجاني، الشريف على بن محمد. كتاب التعريغيات. سقافورة-جدة :خرمين للطب عة والشر والتوزيع، دون السنة.

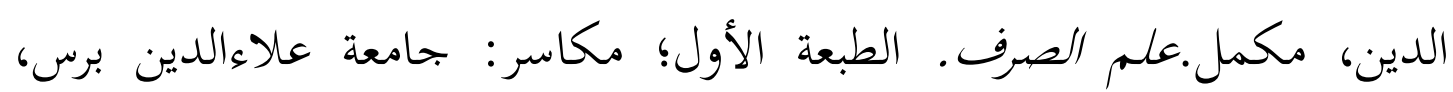
.2013

أوندينغ، شريف الدين. علوم القرآن. الطبعة الأول؛ مكاسر: الجامعة علاء الدين

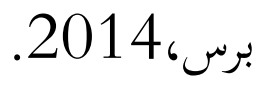

الراجحي، عبده. التطبيق الصرفي. بيروت: حار النهجة العربية،1973م. ئهاب.

-------- التطبيق الصرفي. إسكندرية: دار المعرفة الجامعية، 1989.

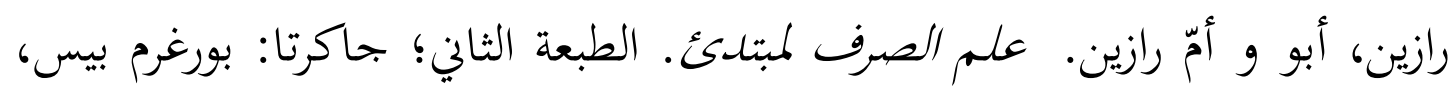
. 2014

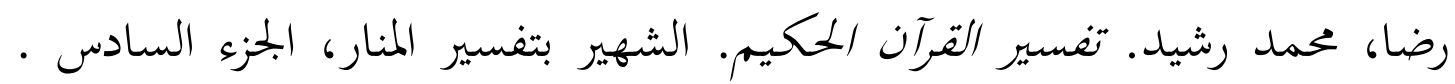

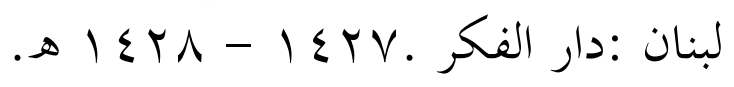

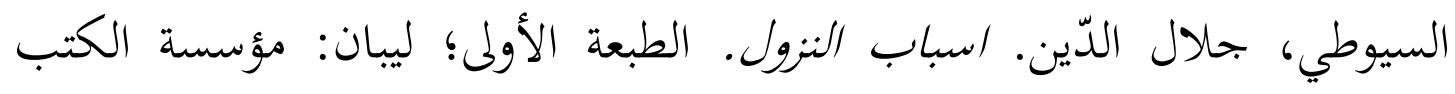

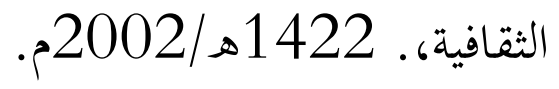

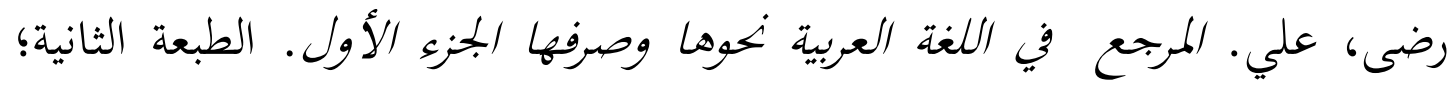
القاهرة: دار الفكر، دون السنة.

عاشور، محمد الطاهر ابن. سير التحرير والتنوير. تونس: دار سخنون للنشر دورن 84 والتوزيع. مختل السنة. 
Shaut Al-'Arabiyah

P-ISSN : 2354-564X

E-ISSN : 2550-0317

الغلاييني، مصطفى. جامع الدروس العببية. الطبعة الثامنة و الثلاثون؛ بيروت: المكتبة العصرية، 2000.

-------.- الدووس العربية للملدس الإبتدائية. بيروت :دار الكتب العلمية،

$$
\cdot r \cdot \cdot v
$$

-------- جامع الدووس العربية. الطبعة الثانية؛ القدس للنشر والتوزيع، 2012

فهمي، أكروم. Ilmu Nahwu dan Sharaf. الطبعة الثاني؛ جاكرتا: بت. راجا غرافيندو بير سادا، 2000.

القطان، مناع. مباحش في علوم القرآن. دم: منشورات العصر الحديث،

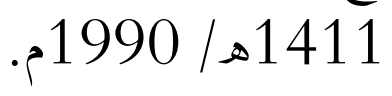

المراغي أحمد مصطفى و محمد سلم، تمذيب التوضيح. الطبعة الأول؛ مكتبة الرشد .2009. :

معروف، نايف. قواعد النحو الوظيفي دارسة و تطبيق. الطبعة الثانية؛ بيروت: دار

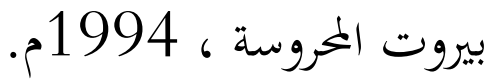

موليونج، ليكسي. Metodologi Penelitian Kualitatif . . باندونغ :بت .رماجا روسدكريا،

الواحدي، الإمام أبي الحسن علي بن أحمد. أمباب نزول القرآن. الطبعة الأولى؛

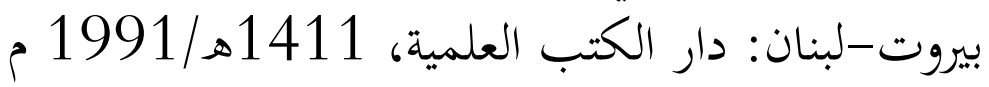

الهدى، اندس محمد شمس و اندس وجود اوطاما ـالتتمة ـالددرسة العالية الحكومية : بحر العلوم تامباء براس جومبانخ لستل السنة.

215 